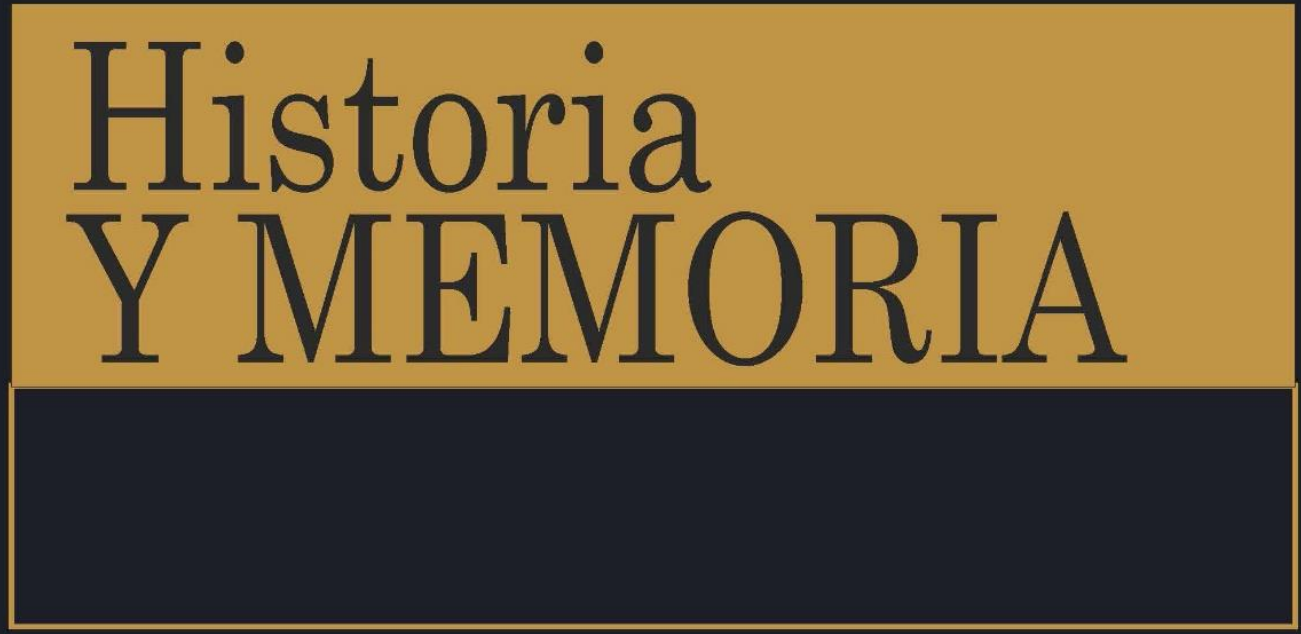

ISSN: 2027-5137 Número Especial • 10 Años • Año 2020 - Tunja, Colombia

\title{
La larga marcha de la historia europea
}

https://doi.org/10.19053/20275137.nespecial.2020.11582

Serge Gruzinski

Páginas 81-101

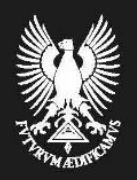




\title{
La larga marcha de la historia europea*
}

\author{
Serge Gruzinski ${ }^{1}$ \\ École des Hautes Études en Sciences Sociales- EHESS- \\ Francia
}

Recepción: 05/02/2020

Evaluación: 11/06/2020

Aprobación: 01/07/2020

Artículo de Investigación e Innovación

https:/doi.org/10.19053/20275137.nespecial.2020.11582

\section{Resumen}

Hoy en día, las ciencias sociales deben circular por los mundos islámico, africano, asiático y occidental, porque el discurso europeo ya no puede pretender ser el discurso universal. En 1517, hace quinientos años, la reforma de Lutero fracturó Europa. Ese mismo año, los conquistadores españoles toman México, colonizándolo y cristianizándolo. También introducen nuestra forma de escribir historia. Los vencedores lo ignoran todo sobre las sociedades indígenas. Pero, para imponer $\mathrm{su}$ ley, deben conocer imperativamente las costumbres $\mathrm{y}$, por tanto, el pasado de los vencidos. ¿Pero qué son la historia y el tiempo en la mente de los indios? El tiempo aún no es un valor universal. ¿Cómo hubieran podido los españoles, formados en una Europa cristiana donde la historia es cronológica y orientada, para concebir y aceptar la

\footnotetext{
* Este ensayo forma parte del volumen La machine à remonter le temps. Quand l'Europe s'est mise à écrire l'Histoire du monde (París: Fayard, 2017). Dicho libro será publicado por FCE con el título: La máquina del tiempo. Cuando Europa comenzó a escribir la historia del mundo, con traducción de José Andrés Ancona Quiroz. Agradecemos al autor y a la editorial la amable cesión de los derechos de esta versión para publicarla y difundirla en Historia Y MEMORIA. La traducción de este texto fue realizada por el Dr. Anaclet Pons. Este y el resto de libros del profesor Gruzinski en FCE se pueden encontrar en: https://bit.ly/2VGCzPj.

1 Doctor en historia, especializado en temas latinoamericanos. Director de investigaciones del Centre National de la Recherche Scientifique y director de estudios de la École des Hautes Études en Sciences Sociales. $\square$ serge.gruzinski@ ehess.fr.
} 
cosmología mesoamericana? ¿Civilizados contra bárbaros? En unas pocas décadas, la máquina del tiempo de los invasores se emplea para capturar los recuerdos de las sociedades nativas amerindias, para fabricar un pasado que pueda vincularse con el antiguo patrimonio de la cristiandad. El autor ofrece, pues, una exploración original de los comienzos de la expansión colonial y explica cómo, sobre el terreno, los religiosos y los indios comienzan a escribir la historia del mundo.

Palabras clave: Europa, América, Historia Global, Historia colonial, Eurocentrismo.

\title{
The long march of European history
}

\begin{abstract}
These days, the social sciences must circulate through the Islamic, African, Asian, and occidental worlds because the European discourse can no longer be seen as the universal discourse. In 1517, more than 500 years ago, the Lutheran Reformation fractured Europe. That very same year, the Spanish conquistadors took over Mexico, colonizing and christianizing it. They also introduced the way in which we write history. The conquerors were completely ignorant about the indigenous societies. However, in order to impose their laws, they had to learn about their customs and, therefore, the past of those they conquered. But, what is history and time in the mind of the indigenous peoples? Time was not yet a universal value. How could the Spaniards, formed in a Christian Europe where history was chronological and focused, understand and accept Mesoamerican cosmology? The civilized against barbarians? In a few decades, the "time machine» of the invadors was used to capture the memories of the Amerindian native societies in order to fabricate a past that could be linked with the ancient heritage of Christianity. The author offers an original exploration of the beginning of the colonial expansion and explains how across the territory, the religious and the indigenous peoples began to write a history of the world.
\end{abstract}

Key Words: Europe, America, Global history, Colonial history, Eurocentrism. 


\section{La longue marche de l'histoire européenne}

\section{Résumé}

Aujourd'hui, les sciences sociales doivent circuler dans les mondes islamique, africain, asiatique et occidental, car le discours européen ne peut plus se prétendre universel. En 1517, il y a 500 ans, la réforme de Luther a brisé l'Europe. Cette même année, les conquérants espagnols sont arrivés au Mexique pour le coloniser et le christianiser. De plus, ils ont introduit notre manière d'écrire l'histoire. Les vainqueurs ignoraient tout sur les sociétés indigènes. Or, pour imposer sa loi, ils devaient absolument connaître les mœurs et, de ce fait, le passé des vaincus. Toutefois, il fallait comprendre ce que c'étaient l'histoire et le temps dans l'esprit des indigènes. Le temps n'était pas encore une valeur universelle. Comment les espagnols, formés dans une Europe chrétienne où l'histoire était chronologique et avait une orientation, ont compris et accepté la cosmologie mésoaméricaine? Civilisés contre barbares? Pendant quelques décennies, la machine du temps des envahisseurs s'adonnait à capter les souvenirs des sociétés natives amérindiennes afin de fabriquer un passé qui puisse se lier à l'ancien patrimoine de la chrétienté. Cet article explore les débuts de l'expansion colonial et tente d'expliquer comment, sur le terrain, les religieux et les indiens ont commencé à écrire l'histoire du monde.

Mots-clés: Europe, Amérique, Histoire global, histoire coloniale, eurocentrisme.

\section{Introducción}

«Navegazioni», "dilatação», navegaciones, expansión: las palabras de los contemporáneos son explícitas para evocar los grandes descubrimientos y la expansión marítima. Los europeos del siglo XV dejan de estar confinados dentro de sus paisajes tradicionales en los que vivieron durante siglos. Van a dirigirse a todas las otras partes del mundo y estas otras partes serán tanto el África de los esclavos, la China de los 
Ming, la India de Vijayanagar, las Molucas de las especies, las Américas de México y del Cuzco.

Movilidad en todos los azimuts: "Hoy día los hombres pasan el mar Océano de cualquiera parte a cualquiera otra que se les antoja» ${ }^{2}$. Poco a poco los territorios lejanos revelan que albergan civilizaciones que dejan atónitos a los visitantes. En adelante, pueden pasearse por las calles de Pekín, por las de México-Tenochtitlan o por Vijayanagar en la India meridional, según leemos en los relatos de Tomé Pires, Hernán Cortés o Fernão Nunes. Estas cercanías desconciertan a los europeos que se interrogan acerca de los medios para llevar a cabo con seguridad su penetración comercial en esas partes o su empresa colonial y religiosa. Las primeras respuestas aparecen en los relatos que describen la llegada de los precursores y las nuevas comarcas que descubren: cartas, diarios de viaje y relaciones que se destinan a un público europeo reúnen toda suerte de informaciones sobre la geografía, la fauna, la flora, como también sobre las poblaciones y los recursos que se espera sacar de esas tierras.

\section{La historia desembarca en América}

En las islas del Caribe, las memorias se extinguen en poco tiempo, tan diezmadas están las sociedades indígenas por las enfermedades, las masacres y la explotación caótica que desencadena esta primera colonización. Hay que tener el buen ojo del cronista español Gonzalo Fernández de Oviedo para localizar las fuentes indígenas que ayuden a remontar el tiempo. Las danzas rituales todavía marcan la existencia de las poblaciones. Intrigan al cronista de Indias. Este se da cuenta de que es el instrumento predilecto que moviliza la memoria indígena para relatar el tiempo anterior a la Conquista:

Tenían estas gentes una buena é gentil manera de memorar las cosas passadas é antiguas; y esto era en sus cantares é bayles, que ellos llaman areyto, que es lo mismo que nosotros llamamos baylar cantando. [...] En su cantar diçen sus

2 José de Acosta, Historia natural y moral de las Indias (México: FCE, 1979), 47. 
memorias é historias passadas, y en estos cantares relatan de la manera que murieron los caçiques passados, y quántos y quáles fueron, é otras cosas que ellos quieren que no se olviden ${ }^{3}$.

Los cantos funcionan como libros que inscriben en la memoria indígena las genealogías de caciques y príncipes, sus proezas y todo lo que era deseable transmitir a la posteridad. Aun cuando fuera tachado a menudo de racista con respecto a los indios, Oviedo es uno de los raros europeos que reconoce que tenían una memoria histórica que no estaba anclada en la práctica de la escritura. El cronista deconstruye incluso el contraste que hace del Nuevo Mundo una tierra de arcaísmo comparado con la cristiandad: cierto número de costumbres son análogas en una y otra parte del océano. Si las cosas de las Indias parecen tan nuevas, es porque son muy antiguas y han caído en el olvido entre nosotros. No se trata de rechazar sistemáticamente al no europeo por una diferencia negativa, condenándolo a recuperar los atrasos acumulados. La idea según la cual los inventos -las bebidas fermentadas, los espejos, las murallas- han aparecido en el Nuevo Mundo, sin tener ningún nexo con su contraparte europea, contribuye igualmente a anular el postulado de la anterioridad histórica del Viejo Mundo o, al menos, a modular significativamente su aplicación. Permanece en pie, sin embargo, que, para escribir una historia, serían necesarios materiales que las islas diezmadas ya no están en grado de proporcionar.

A partir de 1517, la irrupción en las costas mexicanas, luego la penetración en el interior del altiplano, cambian radicalmente la situación. Los españoles se topan con poblaciones numerosas, establecidas en ciudades, que evolucionan en medio de arquitecturas grandiosas que les recuerdan las mezquitas de España. Estas sociedades practican tanto la guerra como el comercio de larga distancia, celebran cultos impresionantes y reclutan ejércitos. Abundan

3 Gonzalo Fernández de Oviedo, Historia General y Natural de las Indias, islas y tierra firme del mar Océano, I, V, cap. 1, vol. 117 (Madrid: Atlas-BAE, 1959), 114; Antonello Gerbi, La naturaleza de las Indias Nuevas (México: FCE, 1978); David A. Lupher, Romans in a New World. Classical Models in Sixteenth Century Spanish America (Ann Arbor: The University of Michigan Press, 2006), 244-245. 
las comparaciones: México y Venecia, Tlaxcala y Pisa. Los primeros visitantes castellanos, que aún no se han vuelto conquistadores, toman consciencia de la gran brecha que separa el continente de las islas del Caribe. La presa será más difícil de atrapar, pero ya es presagio de riquezas inauditas.

Antes incluso de que la conquista se ponga en marcha, Hernán Cortés es quien plantea la cuestión del pasado amerindio. Según la versión que da de su primera entrevista con Moctezuma, el príncipe que lo acoge le habría hecho un relato de los orígenes que legitimaba su presencia y la cesión a Carlos V de las tierras mexicanas ${ }^{4}$. Los españoles no hacían así otra cosa que volver a tomar posesión de un reino abandonado por ancestros lejanos. La carta de relación que Cortés dirigió al emperador colocó claramente la primera piedra de una historia prehispánica captada desde la perspectiva de la invasión europea. La máquina del tiempo ha sido puesta en movimiento: «En consecuencia, pues, la historia mexicana es la que otorga el dominio, la soberanía, al rey de España sobre el territorio mexica ${ }^{5}$.

\section{La captura de las memorias}

Diez años más tarde, la administración española mide la inmensidad de la tarea con la que se ve confrontada. La conquista ya está consumada y el caos acompaña el nacimiento difícil de una sociedad de un género nuevo, en donde están condenados a vivir juntos clanes de colonos ávidos, élites indígenas carentes de reclasificación y masas destinadas al trabajo forzado cuando sobreviven a las epidemias. ¿Cómo conocer estas comarcas que ahora se encuentran en las manos de la corona de Castilla? A los ojos del Consejo de Indias -la instancia suprema que administra los nuevos territorios-, la viabilidad de la dominación española implica la implementación de un poder eficaz. ¿Cómo convertir lo que

4 Hernán Cortés, Cartas y Documentos, ed. Mario Hernández Sánchez-Barba (México: Editorial Porrúa, 1963), 59.

5 Mario Hernández Sánchez-Barba, «Hernán Cortés, delineador del primer estado occidental en el Nuevo Mundo,» Quinto Centenario Vol. 13, (1987): 25. http://revistas. ucm.es/index.php/QUCE/article/view/QUCE8787220017A. 
aún subsiste de las sociedades indias en el fundamento de una dominación por el momento muy precaria aún? Dicho de otra manera, ¿cómo pasar del mundo prehispánico al mundo colonial, cuando nadie puede imaginar los obstáculos que hay que superar ni los medios que hay que movilizar?

Hacia 1530, las autoridades coloniales improvisan. Raros son los españoles que tienen ideas precisas sobre lo que será la Nueva España. A excepción quizás del puñado de altos funcionarios y jueces enviados por Carlos $\mathrm{V}$ y de algunos franciscanos que se ocupan de la evangelización del país. A ellos toca paliar lo más pronto posible la carencia de informaciones y hacer una evaluación de esta nueva tierra. La decisión parte de Madrid el 12 de julio de 1530:

Otrosí que vean la orden y manera de biuir que en los mantenimientos y policia tienen los naturales indios [...] y que entre tanto se guarde de sus buenos vsos y costumbres que en los mantenimientos y policía tienen los naturales yndios en lo que no fueren contra nuestra religión christiana ${ }^{6}$.

En 1533, Carlos V quiere saber todavía más: «Queremos tener un conocimiento completo de las cosas de esta tierra (...), de las poblaciones que se encuentran en ellas con sus ritos y sus costumbres» ${ }^{7}$. Todavía en 1533, el franciscano Andrés de Olmos, «el mejor conocedor de la lengua mexicana que entonces había en esta tierra, y hombre docto y discreto», fue encargado de escribir un libro sobre las antigüedades de estos indios,

[...]en especial de México, y Tezcuco, y Tlaxcala, para que de ello hubiese alguna memoria, y lo malo y fuera de tino se pudiese mejor refutar, y si algo bueno se hallase, se pudiese

6 Vasco de Puga, Cedulario, vol. I, El Sistema Postal (México: Taurus, 1878-1879), 206-207.

7 Victoria Ríos Castaño, Translation as Conquest, Sahagún and the Universal History of the Things of New Spain (Madrid: Iberoamericana, 2014), 100; Francisco de Solano, Cuestionarios para la formación de las relaciones geográficas (Madrid: CSIC, 1988), vol. I, 4. 
notar, como se notan y tienen en memoria muchas cosas de otros gentiles ${ }^{8}$.

La máquina del tiempo está lista para arrancar con sus dos palabras maestras: conservar y seleccionar.

¿Qué busca saber la administración castellana? La curiosidad apremiante que tiene la Corona atañe tanto a los tributos tradicionales y a los derechos de la nobleza indígena como también a la naturaleza de la esclavitud. La información recogida es de naturaleza económica y sociológica y, por tanto, necesariamente histórica ${ }^{9}$. Porque ¿cómo legislar sin conocer los precedentes locales y sin abrevarse en las memorias indígenas? En realidad, las demandas de información no son nuevas. Las primeras se remontan a 1523 . Se reiteran en 1530 , en 1533, en 1536. A mediados del siglo, en 1553, la Corona no se dará todavía por satisfecha.

Para conocer los mecanismos del tributo indígena, es conveniente saber quién paga qué, cómo, a quién y a qué plazo. De donde provienen las primeras encuestas de campo: las autoridades españolas recurren a los archivos, en este caso a los «libros de pinturas» que conservan los indígenas, movilizan a los notables capaces de interpretarlas, convocan a los responsables de la recaudación del tributo. Es necesario entenderse con los escribanos (tlacuilos) que han redactado los registros. Quiérase o no, se establecen contactos, y a veces complicidades, entre élites locales, funcionarios españoles y colonos emprendedores.

\footnotetext{
8 Gerónimo de Mendieta, Historia Eclesiástica Indiana (México: Salvador Chávez Hayhoe, 1945), t. I, 1, II, 81. El tratado - «muy copioso» sobre las «antiguallas»- fue terminado entre 1536 y 1546 y se han perdido sus copias; Georges Baudot, Utopie et histoire au Mexique. Les premiers chroniqueurs de la civilisation mexicaine (15201569) (Tolosa: Privat, 1977), 130; Miguel León-Portilla, «Ramírez de Fuenleal y las antigüedades mexicanas,» Estudios de cultura náhuatl, n 8 (1969): 36-38; Ríos Castaño, Translation as Conquest, 100, 101; S. Jeffrey K. Wilkerson, «The Ethnographics Works of Andrés de Olmos, Precursor and Contemporary of Sahagún,» en Sixteenth Century Mexico: The Work of Sahagún, ed. Munro S. Edmonson (Albuquerque: University of New Mexico Press, 1974), 27-78.
}

9 Baudot, Utopie et histoire, 44. 
Para explotar más eficazmente la mano de obra indígena, es mejor conocer también cuáles eran el estatus y el origen de los esclavos. ¿Y cómo identificar colaboradores dignos de crédito sin informarse de las reglas y modos de funcionamiento de los señoríos indígenas, los cacicazgos? No se sabría cómo confirmar «los privilegios, preeminencias, señoríos y libertades» sin hacer una breve investigación histórica. Por ejemplo, sobre

[...] la forma y el orden que "hasta aquí" ha auido en essa prouincia y en otras subjetas á essa audiencia, en la eleccion é nombramiento de los caciques que en ellas ha auido é ay, asi antes que se pusiesen debaxo de nuestro yugo y señorío real $^{10}$.

A fuerza de preocuparse de lo que ha existido "hasta ahora" o de lo que se practicaba "antes de» la Conquista, a fuerza de multiplicar las preguntas, de recoger respuestas siempre fragmentarias, a veces contradictorias, se va perfilando una exigencia más ambiciosa: conocer el pasado de los indios de la Nueva España. Los jueces de México y los misioneros que siguieron sus pasos ignoraban que estaban desencadenando sobre el continente americano una de las formas más insidiosas, si no es que una de las más acabadas de la expansión occidental: la captura de las memorias.

\section{De Madrid a Calcuta}

Los acontecimientos de México iban a repetirse en otras partes del globo. Todas las administraciones coloniales se esmerarían en lanzar las redes de la historia europea sobre las sociedades locales que pretendían controlar. Modernización e historia a la europea terminarán identificándose hasta el punto de que los países que se libraron de la dominación occidental se sumaron a aquellos que ya la padecían inventándose un pasado, un presente e incluso un futuro formateados en nuestra tradición. Hasta que la sombra del modelo viniera a cubrir el conjunto del planeta.

10 Cédula real dada en Valladolid en diciembre de 1550, en Puga (1878-1879), II, 98-99. 
Se acostumbra a relacionar la ofensiva mundial de la Historia con las Luces. Mismas causas, mismos efectos, o casi: a medida que las potencias europeas amplían su dominio y control del mundo, se esfuerzan en conocer mejor las sociedades que se disponen a explotar. Como en México en los años 1530, los representantes de Gran Bretaña en India se hacen preguntas acerca del pasado del subcontinente ${ }^{11}$. Para estos hombres del siglo XVIII, la historia y la historiografía no pueden más que estar al servicio de la administración imperial $^{12}$.

A dos siglos de distancia, los escenarios no son idénticos, pero a menudo se pueden superponer. Entre ellos flota un aire de parentesco que confirma que nos encontramos frente a una reanudación de la operación iniciada en Nueva España. Aquí también los jueces tienen el control. En este caso, William Jones (1746-1794), Chief Justice de la Suprema Corte de Bengala, cuyas motivaciones habrían podido ser las de los miembros de la Audiencia de México ${ }^{13}$. Ciertamente, en esta época, la corona británica aún no se ha instalado formalmente en el subcontinente y la Compañía de las Indias es la que encarna la colonización inglesa. Esta compañía comienza por emprender el inventario de las tierras y de las rentas que estas producen. Se interesa por las leyes, las lenguas, la religión y por tanto en la historia para comprender los engranajes de este subcontinente inmenso y descubrir por cuál cabo tomarlo. Se recopilan los materiales, se reúnen las fuentes ${ }^{14} \mathrm{y}$ se esboza

11 Michael Gottlob, Historical Thinking in South Asia. A Handbook of Sources from Colonial Times to Present (Nueva Delhi: Oxford University Press, 2005); History and Politics in Post-Colonial India (Nueva Delhi: Oxford University Press, 2011); Ranajit Guha, An Indian Historiography of India: A Nineteenth Century Agenda and its Implications (Calcuta: Centre for Studies in Social Sciences, 1988).

12 Muhammad Shafique Bhatti, «Empire, Law and History: The British Origin of Modern Historiography of South Asia,» Pakistan Journal of Social Sciences, 30.2 (2010): 396.

13 Muhammad Shafique Bhatti, "British Historiography of India: A Study in the Late Eighteenth Century Shift of Interest,» Journal of Pakistan Historic Society, L/2 (2002): 85-104; S. N. Mukherjee, Sir William Jones: A Study in Eighteenth Century British Attitude to India (Cambridge: Cambridge University Press, 1968).

14 Es el caso de un oficial escocés, Colin Mackenzie, que fue el primer Surveyor General of India. 
una primera historia de la India del Sur: Sketches of a History of South India (1810-1817).

Allá, como en México, la escritura de la historia dimana de las exigencias de la administración colonial. La tarea no se impone sino con posterioridad, cuando arrancan los proyectos que ya no se limitan a consignar la historia de las lenguas de la india. Esta bifurcación es contemporánea de la apertura de los colegios de Mádras y Calcuta que tienen por misión formar a los administradores europeos y acoger a las élites indígenas. En estos centros, que muy pronto se han convertido en centros de estudio de las lenguas de la India, se elaboran e imprimen diccionarios y gramáticas. Dos siglos antes, este ya había sido el caso en México: al fundar junto con el virrey el colegio de Santa Cruz de Tlatelolco (1536), los franciscanos se habían procurado los medios para iniciar a los retoños de la nobleza indígena en los saberes europeos y tener una reserva de informantes dóciles que les ayudaran a escribir la historia del país ${ }^{15}$.

Los colegios de Madrás y Calcuta no tardarán nada en producir "un modelo inédito e inesperado para escribir la historia de la India en conexión con la historia del mundo» ${ }^{16}$. En Calcuta, desde 1786, William Jones lanza la idea según la cual hindúes y británicos comparten las raíces indoeuropeas. Treinta años más tarde, esta teoría se enriquece con Francis Whyte Ellis, quien sostiene la existencia de otra familia lingüística: al grupo indo-europeo se agregaría el grupo dravídico. Ellis no es un pionero aislado. Lleva a cabo sus investigaciones rodeado de un equipo compuesto de europeos e indígenas, una colaboración cuya experiencia mexicana proporciona numerosos precedentes. Y su equipo termina generando un modelo histórico que vincula estas teorías lingüísticas con el concepto de raza superior: los pueblos de lengua sánscrita, invasores de piel clara, serían

15 En la India de los británicos como en el México de los conquistadores, estas primeras instituciones educativas se distinguirán por su fragilidad.

16 Thomas R. Trautmann, "Inventing the History of South India," en Invoking the Past: The Uses of History in South Asia, ed. David Ali (Nueva Delhi: Oxford University Press, 2002), 39. 
los civilizadores de la India frente a los dravídicos, bárbaros de tez obscura. El choque de estos dos mundos habría dado a luz el sistema de $\operatorname{castas}^{17}$. Los británicos no tenían que sentir vergüenza de sus primos arios, aun cuando India padeciese la presencia de sociedades consideradas inferiores.

A mediados del siglo XIx ya se instaló el marco en el cual se edificará el pasado de la India ${ }^{18}$. Asimismo, ya están en el país las herramientas para difundirlo. Es considerable la deuda que tienen los europeos con los sabios indígenas. De común acuerdo, británicos e hindúes elaboraron estas teorías, conjugando tradiciones que están lejos de fusionarse siempre con la ciencia moderna.

Uno se puede sorprender de encontrar en India referencias al pasado bíblico de las que no habrían renegado los franciscanos de México. Por ejemplo, para explicar la primacía del sánscrito, se conjugan dos interpretaciones: la idea bíblica de un origen único de las lenguas, el lenguaje adámico, y la tradición de la lingüística brahmánica -el Vyakarana-, que piensa los cambios en términos de decadencia y corrupción ${ }^{19}$. Si Ellis mismo vincula a los dravídicos con los descendientes de Sem, hijo de Noé, Jones había asociado antes de él las lenguas indo-europeas a Cam y otros sabios incluso a Jafet ${ }^{20}$. Misioneros como Robert Caldwell, en una obra que sigue siendo famosa, A Comparative Grammar of the Dravidian of South-Indian Family of Languages (1856) ${ }^{21}$, son quienes discutían estas teorías.

Los evangelizadores de la América ibérica llevaban ventaja: desde hacía más de tres siglos la colonización de las Indias occidentales inspiraba lecturas contradictorias

17 Trautmann, «Inventing the History,» 53.

18 Thomas R. Trautmann, Aryans and British India (Berkeley-Los AngelesLondres: University of California Press, 1997).

19 Trautmann, «Inventing the History,» 44; Eugene F. Irschick, Dialogue and History: Constructing South India, 1795-1895 (Berkeley-Los Angeles-Londres: University of California Press, 1994).

20 Trautmann, «Inventing the History,» 47.

21 Vinay Lal, The History of History. Politics and Scholarship in Modern India (Oxford: Oxford University Press, 2003). 
de la Biblia, en aquellos que querían explicar el origen de las poblaciones amerindias, esos grandes olvidados de la cristianización del mundo.

\section{La historia a la europea: hasta China y Japón}

La Historia se impone en el globo con tanto mayor vigor siempre que no llegue en los equipajes de los colonizadores y los administradores. Este fue el caso en Japón o China. Si en India y Gran Bretaña algunos se permitían sostener que India no había conocido jamás una tradición histórica, la afirmación era insostenible tratándose de China o Japón. En estos dos países, la historia a la europea no penetró con la llegada de los invasores ni siguiendo la estela de las cañoneras, puesto que los historiadores locales mismos la adoptaron por propia iniciativa.

Japón es el que despeja el camino. En el frenesí de modernización que sacude al archipiélago bajo el régimen Meiji, la Historia, del mismo modo que las otras ciencias europeas, resulta ser una adquisición indispensable para que tengan éxito las ambiciones imperiales. Al occidentalizarse, Japón descubre el positivismo. Lee la teoría de la evolución de inspiración darwiniana a la luz de la competencia encarnizada que libran entre sí los grandes países occidentales. Los letrados se sumergen en Histoire générale de la civilisation en Europe (1828-1830) de François Guizot, en Les Origines de la France (1876) de Hyppolite Taine o en History of England (1857) de Thomas Buckle. El traductor de Adam Smith y de Herbert Spencer, Taguchi Ukichi, redacta los seis volúmenes de $A$ Brief History of Japanese Civilization, en los que se afianza la idea de un desarrollo progresivo.

Japón deja entonces de pensarse exclusivamente en comparación con China, «la referencia obligada», para mirarse en el espejo de Occidente. Un espejo que se volvió ineludible porque la difusión de la historia a la europea va a la par del ascenso del nacionalismo moderno y de la reforma del sistema universitario. En 1888 se abre un curso de historia de Japón, luego de «historia nacional» al año siguiente, finalmente de 
historia oriental (Eastern History) en 1904. Se procede así a desmantelar el sistema tradicional de estudios, el bungaku, en cuyo seno, de acuerdo con la tradición china, las Letras absorbían la Historia. En adelante, la Historia, en su formulación occidental, actúa por su cuenta.

Esta disciplina no es importada por los administradores de impuestos desde el exterior, sino que es un asunto de historiadores invitados. Así como Ludwig Riess (1861-1928), un alumno de Leopod von Ranke (1795-1886), reclutado por el gobierno Meiji en 1887, a la edad de 26 años. En la universidad imperial es donde difunde los métodos y los enfoques de su maestro alemán ${ }^{22}$. Mientras los ingleses y los franceses explicaban cómo escribir la historia de la civilización, los alemanes exportaban su método científico que descansaba en el culto a la objetividad y en la nueva figura del universitario de prestigio $^{23}$.

En China, la visión y los métodos europeos se difunden, primero a través de los historiadores japoneses, como Fukuzawa Yukichi (1835-1901) y su historia de la civilización ${ }^{24}$. Entonces es «cuando se pudo abandonar completamente la cosmologización de la historia, profundamente anclada en la idea china de la temporalidad $\iota^{25}$. La adopción de la historia a la occidental se impone como uno de los medios para construir una nación china moderna. En 1920, cuando lanza la nueva historiografía, Liang Quichao (1873-1929) está convencido

22 Ranke desarrolla el sistema de seminario y en 1834 se da a conocer por su libro Die römischen Päpste, ihre Kirche und ihr Staat... Véase: Teijirô Muramatsu, Westerners in the Modernization of Japan, trad. Lynne E. Riggs y Manabu Takeschi (Tokio: Hitachi, 1995).

23 Una apreciación más reservada de la influencia ejercida por Riess se encuentra en Margaret Mehl, "German Influences on Historical Scholarship," en The Past, Present and Future of History and Historical Sources. A Symposium to Commemorate 100 years of Publication of the Historiographical Institute. (Tokio: University of Tokio, 2002), 225-246; Sebastian Conrad, "What Time in Japan? Problems of Comparative Historiography,» History and Theory, 38-1 (1999): 67-83; Francine Hérail, «Regards sur l'historiographie de l'époque Meiji,» Storia della storiografia, 5 (1984): 92-114.

24 Edward Wang, Inventing China through History (Albany: Suny Press, 2001).

25 Léon Vandermeersch, "La conception chinoise de l'histoire,» en La Pensée en Chine aujourd'hui, ed. Anne Cheng (París: Gallimard, 2007), 53. En 1928 se funda el Instituto de investigaciones filológicas e históricas (63). 
de que el ascenso de los nacionalismos europeos y el auge de esta parte del mundo están ligados al estudio de la Historia, pero de una historia que no debe nada a la tradición china (zhengshi). El presente deja de percibirse como el equivalente del pasado, la investigación histórica no es más un simple comentario a las fuentes, reducido a una crítica de tipo filológico; sin embargo, las ideas occidentales chocan en este punto con una tradición formidable, sin duda la más continua en la historia del mundo, que descansa sobre los hombros de pensadores de la talla de Sima Qian (145/86 a. C.) y Sima Guang (1019-1086) y difundida por una literatura pletórica (cerca de 140000 volúmenes) ${ }^{26}$.

Como Japón, China debe pensarse en el espacio-mundo. Este redimensionamiento planetario implica una constante necesidad de oponer lo moderno a lo antiguo, identificándose lo moderno con la aportación europea y lo antiguo con la tradición asiática. Tales preocupaciones ya afloran bajo la pluma de los historiadores de la Nueva España y de Perú, quienes, lo vamos a ver, trasladan al espacio atlántico la fractura temporal que los italianos del Renacimiento introdujeron en el pasado europeo.

En Japón, India o China, la historia a la europea y el historicismo acompañan la aparición de los nacionalismos locales. Allá, y en todas partes fuera de Europa, el historicismo no se limita a inculcar otras maneras de considerar el tiempo y construir el pasado local. Su impronta impone la idea de un tiempo único y uniformemente lineal, estipulando que una sociedad, sin importar dónde se encuentre, no puede pensarse sino a partir de su inscripción en la historia y recortada en una serie de categorías preestablecidas. En esta perspectiva, lo social, lo político, lo religioso, lo cultural, aparecen como determinados históricamente ${ }^{27}$.

26 Vandermeersch, «La conception chinoise,» 70.

27 Dipesh Chakrabarty, Provincializing Europe: Postcolonial Thought and Historical Difference (Princeton: Princeton University Press, 2000), 22. [trad. cast,: Al margen de Europa (Barcelona: Tusquets, 2008), 52-53]. 
$\mathrm{Al}$ adoptar los métodos y las perspectivas de Occidente, las élites locales tienen a su vez la intención de construir una nación dotándola de un pasado replanteado y haciendo que tome sus distancias respecto de Occidente. Pero, aunque esta historia nacional trata de fijar su posición críticamente o de recuperarse de un supuesto retraso, no hace sino confirmar la penetración del occidentalismo. Este será igualmente el caso de la historia marxista en China $^{28}$ y en algunos historiadores de la India.

En China, esta orientación comienza a ser objeto de debate en los años 1980, bajo la influencia de la historia-mundo, pero el arraigo del modelo (y de la escolástica) marxista -por razones más políticas que intelectuales- impide la ruptura con el eurocentrismo. Como lo estipula el discurso oficial en nombre de la gran saga de los modos de producción, el motor del desarrollo histórico sigue siendo el monopolio y el legado de la Europa moderna. Aun cuando la historia mundial publicada en 1994 haga a un lado la lucha de clases, la historia moderna se sigue concibiendo como la de los Grandes Descubrimientos, la de la emergencia y expansión del capitalismo. ¿Su tesis? En el siglo XIX y a partir de la Europa occidental es que se realiza plenamente la historia-mundo, ocupando Europa y Estados Unidos cerca de las cuatro quintas partes del texto. Paradójicamente, la revaluación de la parte de China en la historia medieval y moderna se debe, por otro lado, mucho más a iniciativas provenientes de Estados Unidos que a propuestas chinas, pues acercar marxismo y eurocentrismo o aminorar el atraso de una China imperial corre el riesgo de poner en entredicho la legitimidad de la revolución comunista.

La historia del mundo sigue siendo la historia de la modernización: al ritmo del capitalismo, esta disciplina europea se ha mundializado.

28 El principal introductor fue Guo Moruo (1892-1978): Arif Dirlik, «Provincialiser le capitalisme: le cas de l'historiographie chinoise», Période, http://revueperiode.net/ provincialiser-le-capitalisme-le-cas-de-lhistoriographie-chinoise/28. Chakrabarty, Provincializing Europe... 


\section{5. "Provincializar a Europa»}

El despliegue de los modelos históricos europeos, y del historicismo que estos vehiculan, obliga a cuestionarse por la legitimidad, la universalidad y los límites de la disciplina que llamamos Historia. Es lo que había expuesto magistralmente el historiador Dipesh Chakrabarty en su libro Al margen de Europa $^{29}$. Los criterios que definen la historia para nosotros son exclusivamente eurocéntricos. Lo cual implica que las sociedades locales se miden de acuerdo a sus capacidades para replicar el modelo europeo; dicho de otra manera, para repetir una historia que ya sucedió en otras partes. A riesgo de ser tachadas de ignorantes o de gusto excesivo por el pasado, estas sociedades se ven constreñidas en adelante a mirarse en el espejo occidental. Explícitamente o no, la historia de Europa se afirma como la referencia obligada, aun cuando siga sirviendo de repelente. En este juego, todas las otras historias se reducen a intentos más o menos logrados de alcanzar al grupo delantero que constituye el Occidente. Se miden los retrasos, se detectan los obstáculos, se evalúan los fracasos: el tiempo histórico sirve para medir la distancia cultural que supuestamente separa a Occidente del resto del planeta.

En el siglo XIX, el Estado nacional, la ciudadanía, los valores burgueses, la separación de lo público y lo privado, y el capitalismo definen la modernidad que los europeos proponen como ejemplo al resto del mundo. Tres siglos antes, los valores del cristianismo y las ambiciones del humanismo, las Leyes de Indias, y las del capitalismo mercantil, son los principales resortes de la modernidad ibérica. En esta época, lo moderno todavía tiende a confundirse con los valores de la cristiandad latina. Pero la parte del mundo que iba a llegar a ser la Europa occidental se presenta de ahora en adelante como «la cuna originaria de la modernidad» y las otras naciones, colonizadas o no, deben inspirarse en ella.

Para estos países, el tiempo de la historia se plantea entonces no solo en términos de distancia y recuperación,

29 Chakrabarty, Provincializing Europe... 
sino también de transición de los mundos arcaicos al mundo moderno. ¿Cómo superar los obstáculos tecnológicos, institucionales, políticos que ponen trabas a esta "necesaria» e «ineluctable» marcha hacia adelante? En concreto, ¿cómo pasar, en el siglo XIX, de las sociedades tradicionales de África y Asia al universo de la revolución industrial? Tres siglos antes, las poblaciones sobrevivientes del Nuevo Mundo habían sido invitadas a sumarse a la historia del cristianismo, de Castilla y de Portugal, a abandonar la edad del Neolítico para abrazar la edad de Hierro. Como fueron forzadas siglos más tarde a abrazar la vulgata marxista o a someterse a los dictados del liberalismo ${ }^{30}$.

Toda transición arranca con una ruptura: la Conquista, la colonización, la cristianización, la mundialización son otros tantos años cero que marcan la entrada en la Historia, al menos en una historia europea y occidental. En el año 2000, extremo caso de amnesia, Brasil festejó, sin parpadear, o casi, sus cinco siglos de existencia, mientras que el hombre está presente sobre la faz de esta tierra desde hace más de quince mil años. Pero no siempre se puede prescindir del pasado: si en Perú, México y otros países de América la escritura de la historia pasa sistemáticamente por la introducción de pasados no europeos, la historiografía occidental sigue trazando la línea divisoria: esos tiempos serán precolombinos, prehispánicos, precortesianos: no son más que «prehistorias»... Así, la Historia «es precisamente el lugar donde se desarrolla la lucha por apropiarse, en nombre de lo moderno (mi Europa hiperreal), de esas otras disposiciones de la memoria». ${ }^{31}$

\section{Bibliografia}

Acosta, José de. Historia natural y moral de las Indias. México: FCE, 1979.

30 En este espíritu es como durante décadas, con la convicción de poseer una verdad de fe, los especialistas de América latina van a debatir acerca de la transición del modo de producción asiática al modo de producción colonial.

31 Chakrabarty, Provincializing Europe..., 37. [ Al margen de Europa, 69]. 
Baudot, Georges. Utopie et histoire au Mexique. Les premiers chroniqueurs de la civilisation mexicaine (1520-1569). Tolosa: Privat, 1977.

Bhatti, Muhammad Shafique. "British Historiography of India: A Study in the Late Eighteenth Century Shift of Interest.» Journal of Pakistan Historic Society, L/2 (2002): 85-104.

Bhatti, Muhammad Shafique. «Empire, Law and History: The British Origin of Modern Historiography of South Asia.» Pakistan Journal of Social Sciences, 30. 2 (2010): 389-400.

Chakrabarty, Dipesh. Provincializing Europe: Postcolonial Thought and Historical Difference. Princeton: Princeton University Press, 2000 [Al margen de Europa. Barcelona: Tusquets, 2008].

Conrad, Sebastian. «What Time in Japan? Problems of Comparative Historiography.» History and Theory, 38-1 (1999): 67-83.

Cortés, Hernán. Cartas y Documentos, editado por Mario Hernández Sánchez-Barba. México: Editorial Porrúa, 1963.

Dirlik, Arif. «Provincialiser le capitalisme: le cas de l'historiographie chinoise", Période, http://revueperiode.net/provincialiserle-capitalisme-le-cas-de-lhistoriographie-chinoise/28. [Aparecido inicialmente como «Marxisme et histoire chinoise: la globalisation du discours historique et la question de l'hégémonie dans la référence marxiste à l'histoire.» ExtrêmeOrient, Extrême-Occident, 9 (1987): 91-112].

Fernández de Oviedo, Gonzalo. Historia General y Natural de las Indias, islas y tierra firme del mar Océano, I, V, cap. 1, vol. 117. Madrid: Atlas-BAE, 1959.

Gerbi, Antonello. La naturaleza de las Indias Nuevas. México: FCE, 1978.

Gottlob, Michael. Historical Thinking in South Asia. A Handbook of Sources from Colonial Times to Present. Nueva Delhi: Oxford University Press, 2005. 
Gottlob, Michael. History and Politics in Post-Colonial India. Nueva Delhi: Oxford University Press, 2011.

Guha, Ranajit. An Indian Historiography of India: A Nineteenth Century Agenda and its Implications. Calcuta: Centre for Studies in Social Sciences, 1988.

Hérail, Francine. «Regards sur l'historiographie de l'époque Meiji.» Storia della storiografia, 5 (1984): 92-114.

Hernández Sánchez-Barba, Mario. «Hernán Cortés, delineador del primer estado occidental en el Nuevo Mundo.» Quinto Centenario Vol. 13, (1987): 17-36. http://revistas.ucm.es/index. php/QUCE/article/view/QUCE8787220017A.

Irschick, Eugene F. Dialogue and History: Constructing South India, 1795-1895. Berkeley-Los Angeles-Londres: University of California Press, 1994.

Lal, Vinay. The History of History. Politics and Scholarship in Modern India. Oxford: Oxford University Press, 2003.

León-Portilla, Miguel. «Ramírez de Fuenleal y las antigüedades mexicanas.» Estudios de cultura náhuatl, n 8 (1969): 9-49.

Lupher, David A. Romans in a New World. Classical Models in Sixteenth Century Spanish America. Ann Arbor: The University of Michigan Press, 2006.

Mehl, Margaret. «German Influences on Historical Scholarship.» En The Past, Present and Future of History and Historical Sources. A Symposium to Commemorate 100 years of Publication of the Historiographical Institute. Tokio: University of Tokio, 2002.

Mendieta, Gerónimo de. Historia Eclesiástica Indiana. México: Salvador Chávez Hayhoe, 1945.

Mukherjee, S. N. Sir William Jones: A Study in Eighteenth Century British Attitude to India. Cambridge: Cambridge University Press, 1968.

Muramatsu, Teijirô. Westerners in the Modernization of Japan, traducido por Lynne E. Riggs y Manabu Takeschi. Tokio: Hitachi, 1995. 
Puga, Vasco de. Cedulario, vol. I, El Sistema Postal. México: Taurus, 1878-1879.

Ríos Castaño, Victoria. Translation as Conquest, Sahagún and the Universal History of the Things of New Spain. Madrid: Iberoamericana, 2014.

Solano, Francisco de. Cuestionarios para la formación de las relaciones geográficas. Madrid: CSIC, 1988.

Trautmann, Thomas R. Aryans and British India. Berkeley-Los Angeles-Londres: University of California Press, 1997.

Trautmann, Thomas R. «Inventing the History of South India.» En Invoking the Past: The Uses of History in South Asia, editado por David Ali, 36-54. Nueva Delhi: Oxford University Press, 2002.

Vandermeersch, Léon. «La conception chinoise de l'histoire.» En La Pensée en Chine aujourd'hui, editado Anne Cheng, 47-74. París: Gallimard, 2007.

Wang, Edward. Inventing China through History. Albany: Suny Press, 2001.

Wilkerson, S. Jeffrey K. «The Ethnographics Works of Andrés de Olmos, Precursor and Contemporary of Sahagún.» En Sixteenth Century Mexico: The Work of Sahagún, editado por Munro S. Edmonson, 27-77. Albuquerque: University of New Mexico Press, 1974.

\section{Citar este artículo}

Gruzinsky, Serge. "La larga marcha de la historia Europea.» Historia Y MEMORIA, $\mathrm{n}^{\circ}$ Especial (2020): 81-101. DOI: https:/ doi.org/10.19053/20275137.nespecial.2020.11582. 